\title{
Left-Right and Up-Down Mirror Image Confusion in 4-, 5- and 6-Year-Olds
}

\author{
Izumi Uehara \\ Department of Psychology, Ochanomizu University, Tokyo, Japan \\ Email: uehara.izumi@ocha.ac.jp
}

Received July 24 ${ }^{\text {th }}$, 2013; revised August 26 $6^{\text {th }}$, 2013; accepted September $28^{\text {th }}, 2013$

\begin{abstract}
Copyright (c) 2013 Izumi Uehara. This is an open access article distributed under the Creative Commons Attribution License, which permits unrestricted use, distribution, and reproduction in any medium, provided the original work is properly cited.
\end{abstract}

\begin{abstract}
Young children under the age of 8 - 9 years tend to confuse left-right mirror images, and it is thought that their linguistic skills play a crucial role in this phenomenon. However, other aspects of this confusion, such as whether children confuse up-down mirror images or whether the meaningfulness of the stimulus influences matching performance, remain unclear. The present study examined the confusion of left-right and up-down reversed images by 4-, 5- and 6-year-olds using meaningful and meaningless figures in a task in which sample and comparison stimuli were presented simultaneously. Children performed more accurately when presented with meaningful figures and confused both up-down and left-right reversed figures, although they did so less frequently in response to up-down than to left-right reversed figures. Reversal confusion was greatest in 4-year-olds and no significant differences were observed between 5and 6-year-olds. These findings suggest that the ability to discriminate reversed images may be associated with the development of a wide range of cognitive abilities including theory of mind, executive function, and suggestibility.
\end{abstract}

Keywords: Preschool Children; Left-Right and Up-Down Mirror Image Confusion; Meaningfulness

\section{Introduction}

It is well-known that young children under 8 - 9 years of age experience difficulty when discriminating left-right mirror images (e.g., Bryant, 1973; Cohn \& Stricker, 1979; Cronin, 1967; Davidson, 1935; Jordan \& Jordan, 1974; Thompson, 1975). A number of previous studies have used letters, such as "b" versus "d" and "p" versus " $q$ ", to investigate reversal discrimination and, as a result, it is thought that there may be a correlation between the reading and writing skills of children and their performance on left-right reversal discrimination tasks (Cohn \& Stricker, 1979; Cubelli \& Della Sala, 2009; Davidson, 1935; Fisher, Bornstein, \& Gross, 1985; Jordan \& Jordan, 1974, 1990; Terepocki, Kruk, \& Willows, 2002).

McMonnies (1992a; 1992b) found that mirror image confusion in children is correlated with factors other than linguistic skills and suggested that left/right body awareness may be a latent factor. Jean-Paul and Youssef (2012) suggested that other tasks, such as those that require writing a letter in a specific location on a sheet of paper, may also influence the mirror writing of children. Furthermore, meaningfulness has some influence on mirror image discrimination. Mandler and Stein (1974) found that children 7 - 8 years of age recognize reversals of meaningful pictures more accurately than expected, although this study did not include meaningless pictures as control stimuli. Outside of this classic study, the relationship between the meaningfulness of a stimulus and mirror image confusion lacks supporting evidence and, to date, the causes of mirror image confusion in children and the mechanisms underlying this phenomenon remain unclear. Thus, it is important to explore the possible factors other than linguistic skills such as reading and writing, that influence mirror image confusion in preschool children who have not yet fully developed reading and writing skills.

A number of previous studies have used lines and figures to investigate the discrimination of images by preschool children (Bryant, 1973; Corballis \& Zalk, 1977; Cronin, 1967; Rude1 \& Teuber, 1963; Thompson, 1975). However, the type of stimuli that elicit confusion in preschool children and the extent of such confusion remain ambiguous. Likewise, the discrimination of up-down mirror images is much less documented than is left-right reversal discrimination. Several initial studies indicate that up-down discrimination is easier for young children than left-right discrimination (Davidson, 1935; Huttenlocher, 1967; Rude1 \& Teuber, 1963; Thompson, 1975), but these studies do not clarify whether preschool children confuse up-down reversals in a matching-to-sample task involving novel stimuli. Additionally, virtually no studies have investigated up-down discrimination in young children. Thus, the extent to which children confuse up-down reversed images and the age at which such confusion occurs compared with the extent to which they confuse left-right reversed images and the age at which that confusion occurs remain ambiguous.

Thus, the present study examined the extent to which preschool children confuse original figures with left-right and up-down reversals of these images and whether their performance in response to meaningful versus meaningless figures differs. To compare responses to left-right and up-down reversed images, each child was asked to perform a simultaneous matching-to-sample task by selecting a stimulus from a set of 
comparison stimuli that included both left-right and up-down reversed stimuli.

\section{Method}

\section{Participants}

This study included 42 4-year-olds (12 boys and 30 girls; mean age: 4 years and 2 months; range: 3 years and 8 months to 4 years and 6 months), 41 5-year-olds (24 boys and 17 girls; mean age: 5 years and 2 months; range: 4 years and 7 months to 5 years and 6 months), and 45 6-year-olds (26 boys and 19 girls; mean age: 6 years and 2 months; range: 5 years and 7 months to 6 years and 6 months) from a nursery school in a suburb of a large city near Tokyo. All were middle-class, Japanese-speaking children. This study was conducted under the supervision of the school, and written consent from the parents of participants was obtained through the school prior to the participation of their children. All children who participated in this study did so voluntarily and none dropped out before the study was completed.

\section{Materials}

Ten stimulus sheets $(210 \mathrm{~mm} \times 297 \mathrm{~mm}$ ) were used for the test (explained in the next section), and four were used for practice trials that were performed before the test trials. A sample stimulus was presented in the upper half of each stimulus sheet, and six comparison stimuli were presented in the lower half in a $2 \times 3$ layout (see Figure 1). The six comparison stimuli were comprised of the same figure as the sample stimulus (in the upper half), a left-right reversal of the sample stimulus, an up-down reversal of the sample stimulus, and three figures that appeared similar to the sample stimulus. Each of the three figures differed from the sample stimulus in a few respects. For example, if the sample were a shirt, one of the comparison figures would have a crooked sleeve and another would not have a collar (Figure 1).

Thus, 10 sample stimuli and $60(10 \times 6)$ comparison stimuli were used for the test trials, whereas four sample stimuli and 24 $(4 \times 6)$ comparison stimuli were used for the practice trials. The 10 sample stimuli in the test trials consisted of five meaningful figures and five meaningless figures used by a previous study (Uehara, 2012) in which seven elementary school children (aged 7.6 - 9.3 years) correctly chose all the meaningful and meaningless figures. Meaningful figures included a shirt, a cup, and a boot, and meaningless figures were geometrical figures

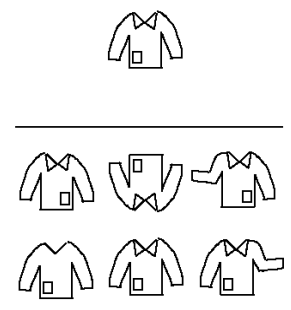

(a)

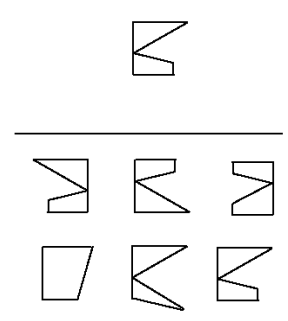

(b)
Figure 1.

Illustration of the placement of stimuli on a test sheet. A sample stimulus was placed on the upper half of the paper, and six comparison stimuli were placed on the lower half. a) An example of meaningful stimuli. b) An example of meaningless stimuli. consisting of lines and curves (Figure 1). The four sample stimuli in the practice trials were simple meaningless figures and were never used in the test trials. All figures were prepared by computer software and hard copies were used for the experiment. The presentation order of the 10 test sheets was randomized across participants, and the locations of the six comparison figures on each sheet were also randomized for each participant.

\section{Procedure}

Each participant performed the task in a quiet classroom during his or her free time during the regular school day. Before the test trials, each subject completed four practice trials and received feedback after each response. By the end of the practice trials, the researcher confirmed that each participant understood the task requirements: namely, to choose the figure that looked most similar to the sample.

For the test trials, the researcher presented each child with 10 figure sheets one at a time. The researcher asked the child to choose the comparison figure that was most similar to the sample figure by asking the child, "Which figure looks most like this figure?” Children responded by pointing with their finger. The test trials did not include feedback concerning the accuracy of the response; rather, the same verbal prompt was given each time, "Well, then, next." All participants finished the test trials in approximately 3 - 5 minutes.

\section{Results}

Preliminary analyses did not reveal any sex differences in accuracy or error type; thus, sex was not considered in the following analyses.

\section{Effects of Age and Meaningfulness on Matching-to-Sample Performance}

The mean correct response rate of the children was plotted as a function of age and meaningfulness (Figure 2), and only an exact match-to-sample response was considered correct. A three (age: 4-, 5-, or 6-year-old) $\times$ two (meaningfulness: meaningful or meaningless) analysis of variance (ANOVA) revealed statistically significant main effects for age $(F[2,125]=53.7$,

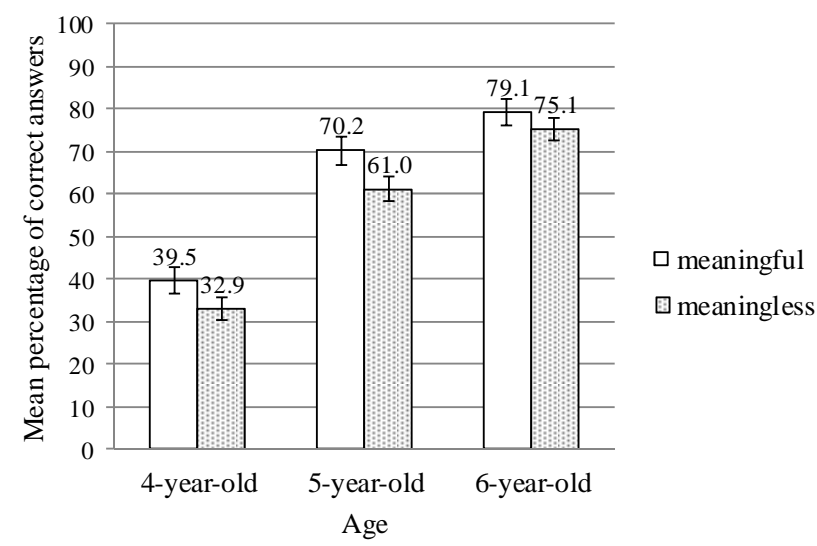

Figure 2.

The mean correct response rate plotted as a function of age (4-year-olds, 5-year-olds, and 6-year-olds) with meaningfulness (meaningful or meaningless figures) as a parameter. Error bars indicate standard errors. 
$p<.01$, partial $\left.\eta^{2}=.46\right)$ and meaningfulness $(F[1,125]=8.79$, $p<.01$, partial $\left.\eta^{2}=.07\right)$. No significant interaction between age and meaningfulness was observed $(F[2,125]=.46 p>.05$, partial $\left.\eta^{2}=.00\right)$. Post hoc multiple comparison tests for age (Tukey $H S D, p=.05$ ) revealed a significantly poorer performance by 4-year-olds compared with 5-year-olds and 6-year-olds and by 5 -year-olds compared with 6 -year-olds. These findings indicate that older children performed better than younger ones and that children performed more accurately in response to meaningful than to meaningless figures.

\section{Analysis of Errors: Choice of Left-Right Mirror Images}

To investigate whether children erroneously chose the left-right reversed stimuli more frequently than expected by chance (chance level: $16.7 \%$ ), one-sample $t$-tests were conducted. Children in each age group chose the left-right reversed stimuli significantly more frequently than chance in response to both meaningful and meaningless stimuli: 4-year-olds for meaningful stimuli: $t(41)=7.37, p<.01$; 4-year-olds for meaningless stimuli: $t(41)=9.40, p<.01 ; 5$-year-olds for meaningful stimuli: $t(40)=4.40, p<.01$; 5 -year-olds for meaningless stimuli: $t(40)=4.65, p<.01$; 6-year-olds for meaningful stimuli: $t(44)=4.29, p<.01$; 6 -year-olds for meaningless stimuli: $t(44)=2.08, p<.05)$. In other words, when children failed to choose the exact match, they chose the left-right reversed stimulus more frequently, regardless of meaningfulness.

Differences in the choice of left-right mirror images according to age and meaningfulness were also assessed. The mean response rate of the children when choosing left-right reversed stimuli was plotted as a function of age and meaningfulness (Figure 3). A three (age: 4-, 5-, or 6-year-old) $\times$ two (meaningfulness: meaningful or meaningless) ANOVA revealed a statistically significant main effect for age $(F[2,125]=14.8, p$ $<.01$, partial $\left.\eta^{2}=.19\right)$ but not for meaningfulness $(F[1,125]=$ $1.71, p>.05$, partial $\eta^{2}=.01$ ) or for the interaction between these two factors $\left(F[2,125]=1.94 p>.05\right.$, partial $\left.\eta^{2}=.03\right)$. Post hoc multiple comparison tests for age (Tukey HSD, $p$ $=.05$ ) revealed a significantly greater number of choices of the left-right reversed stimulus by 4 -year-olds than by 5 -year-olds

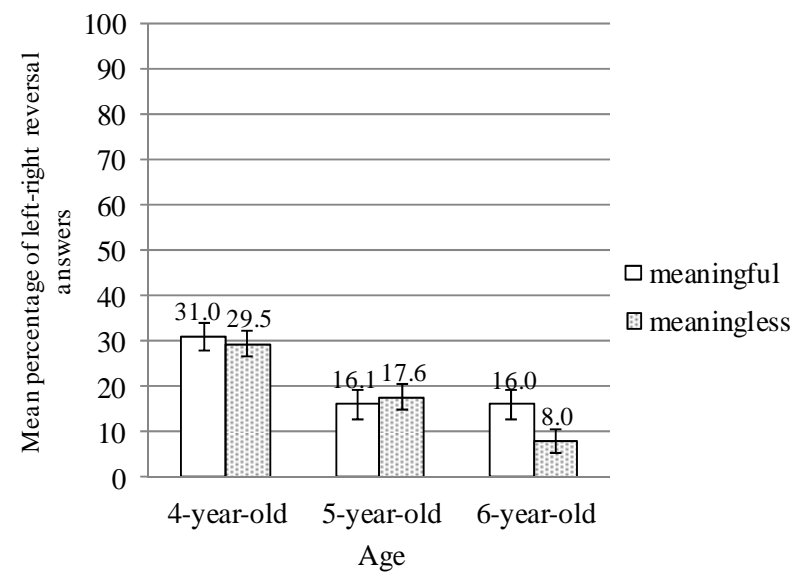

Figure 3.

The mean response rate of children choosing left-right reversed figures plotted as a function of age (4-year-olds, 5-year-olds, and 6year-olds) with meaningfulness (meaningful or meaningless figures) as a parameter. Error bars indicate standard errors. and 6-year-olds. No significant difference was found between 5 -year-olds and 6-year-olds. These findings indicate that young children aged 4 - 6, especially 4-year-olds, often confused figures with their left-right mirror images regardless of meaningfulness.

\section{Analysis of Errors: Choice of Up-Down Mirror Images}

To investigate whether children erroneously chose the up-down reversed stimulus more frequently than expected by chance (chance level: 16.7\%), one-sample $t$-tests were performed. Only the 4-year-olds chose the up-down reversed stimulus significantly more frequently than would be expected by chance regardless of meaningfulness: for meaningful stimuli: $t(41)=3.83, p<.01$; for meaningless stimuli: $t(41)=8.02, p$ $<.01$. The 5-year-olds and 6-year-olds chose the up-down stimulus significantly more frequently than would be expected by chance in response to meaningless but not meaningful stimuli; 5-year-olds for meaningful stimuli: $t(40)=1.53, p>.05$; 5-year-olds for meaningless stimuli: $t(40)=4.39, p<.01$; 6-year-olds for meaningful stimuli: $t(44)=.16, p>.05$; 6 -year-olds for meaningless stimuli: $t(44)=5.83, p<.01$. In other words, when children failed to choose the exact match, 4-year-olds chose the up-down reversed figures more frequently than expected by chance regardless of meaningfulness, whereas 5-year-olds and 6-year-olds chose the up-down reversed stimulus more frequently than expected by chance only in response to meaningless figures.

The mean response rate of children choosing the up-down reversed stimuli was plotted as a function of age and meaningfulness (Figure 4). A three (age: 4-, 5-, or 6-year-old) $\times$ two (meaningfulness: meaningful or meaningless) ANOVA revealed statistically significant main effects for age $(F[2,125]=$ $10.1, p<.01$, partial $\left.\eta^{2}=.14\right)$ and meaningfulness $(F[1,125]=$ 36.7, $p<.01$, partial $\left.\eta^{2}=.23\right)$. The interaction of these two factors was not significant $\left(F[2,125]=.38, p>.05\right.$, partial $\eta^{2}$ $=.00$ ). Post hoc multiple comparison tests for age (Tukey HSD, $p=.05$ ) indicated a significantly greater number of choices of the up-down reversed stimulus by 4-year-olds compared with 5-year-olds and 6-year-olds. No significant difference was

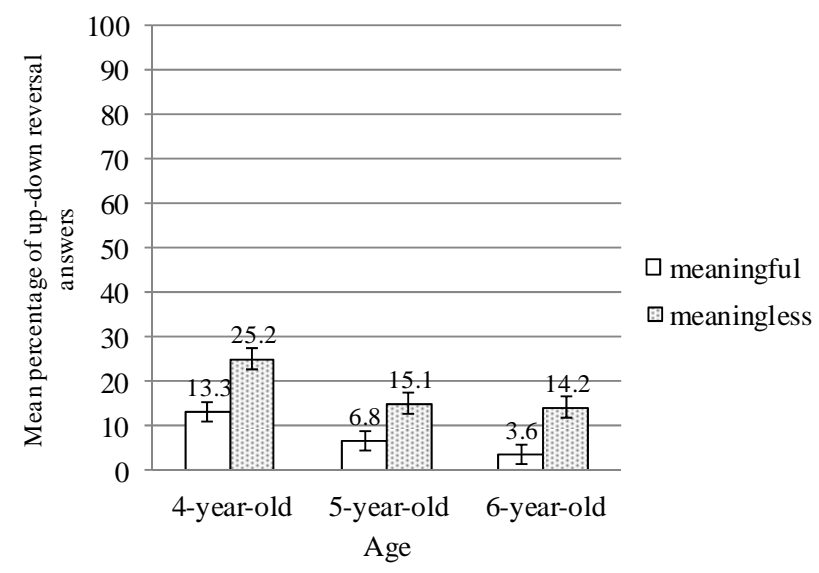

\section{Figure 4.}

The mean response rate of children choosing up-down reversed figures plotted as a function of age (4-year-olds, 5-year-olds, and 6-year-olds) with meaningfulness (meaningful or meaningless figures) as a parameter. Error bars indicate standard errors. 
observed between 5-year-olds and 6-year-olds. These findings indicate that children, regardless of age, chose up-down reversed figures more frequently in response to meaningless than meaningful figures and that 4-year-olds chose meaningful up-down reversed figures more frequently than did older children.

\section{Analysis of Errors: Left-Right Reversed Stimuli versus Up-Down Reversed Stimuli}

The relative frequencies of choosing left-right and up-down reversed stimuli were compared. For meaningful figures, a three (age: 4-, 5-, or 6-year-old) $\times$ two (reversal direction: left-right or up-down ) ANOVA revealed statistically significant main effects for age $\left(F[2,125]=12.5, p<.01\right.$, partial $\eta^{2}$ $=.17)$ and reversal direction $(F[1,125]=33.8, p<.01$, partial $\left.\eta^{2}=.21\right)$. The interaction between these two factors was not significant $\left(F[2,125]=1.14, p>.05\right.$, partial $\left.\eta^{2}=.02\right)$. Post hoc multiple comparison tests for age (Tukey HSD, $p=.05$ ) indicated a significantly greater number of choices of reversed stimuli by 4-year-olds than by 5-year-olds and 6-year-olds, but no significant difference was found between 5-year-olds and 6 -year-olds. In other words, children, regardless of age, chose meaningful left-right reversed figures more often than they chose meaningful up-down reversed figures when they failed to choose the exact match. Additionally, 4-year-olds chose both meaningful left-right and up-down reversed stimuli more frequently than did 5-year-olds and 6-year-olds.

In terms of meaningless figures, a three (age: 4-, 5-, or 6-year-old) $\times$ two (reversal direction: left-right or up-down) ANOVA revealed a statistically significant main effect for age $\left(F[2,125]=23.8, p<.01\right.$, partial $\left.\eta^{2}=.28\right)$. No main effects for reversal direction $\left(F[1,125]=.01, p>.05\right.$, partial $\left.\eta^{2}=.00\right)$ and no interactions between these two factors $(F[2,125]=2.02, p$ $>.05$, partial $\eta^{2}=.03$ ) were observed. Post hoc multiple comparison tests for age (Tukey HSD, $p=.05$ ) indicated a significantly greater number of choices of the up-down reversed stimulus by 4 -year-olds than by 5 -year-olds and 6 -year-olds, but no significant difference was found between 5-year-olds and 6-year-olds. In other words, the difference in the selection of meaningless left-right and up-down reversed figures was not significant, and 4-year-olds chose both meaningless left-right and up-down reversed stimuli more frequently than did 5-yearolds and 6-year-olds.

\section{Discussion}

The present study investigated confusion in preschool children when selecting left-right and up-down mirror images of figures by including meaningful and meaningless figures within the same paradigm. Consistent with previous studies, left-right reversal confusion was frequently observed in children regardless of meaningfulness. Specifically, 4-year-olds confused original figures with their up-down reversals regardless of meaningfulness, whereas 5-year-olds and 6-year-olds confused only meaningless figures. With regard to meaningful figures, children confused the originals with their left-right reversals more frequently than with their up-down reversals; this difference was not significant for meaningless figures. This type of confusion was more frequently observed in 4-year-olds compared with 5-year-olds and 6-year-olds, and we found no difference in the confusion of 5-year-olds and 6-year-olds.
Matching-to-sample performance improved with age between 4 and 6 years, and children performed more accurately for meaningful than meaningless figures.

The present study provides new basic data and insights regarding reversal confusion in young children, and these data suggest that several critical aspects of phenomenon have been overlooked in children. First, up-down reversal confusion in children has rarely been investigated, and knowledge concerning this phenomenon is very limited. In the present study, preschool children confused not only left-right but also up-down reversed images. Additionally, up-down reversal confusion decreased earlier than did left-right reversed confusion. As left-right reversal confusion, such as in mirror writing, is commonly observed when children begin to learn to write, research tends to focus on its relationship to linguistic skills. However, up-down reversal confusion in writing tasks has rarely been investigated in children. The current findings suggest differential associations between up-down reversal confusion and left-right reversal confusion, on the one hand, with linguistic development, on the other, such that up-down confusion depends on factors other than linguistic skills, such as directional or visuospatial sense, whereas left-right confusion depends more on linguistic skills.

Less frequent reversal confusion for meaningful relative to meaningless figures suggests that meaningfulness influences difficulty during the differentiation of stimuli. Thus, if children are encouraged to find meaning in shapes or figures, they might be less confused by reversed shapes. Previous studies indicate that children younger than 8 - 9 years tend to confuse left-right reversed letters. Based on the present findings, the ability to find meaning in a word or to imagine a word from a letter may contribute to avoidance of left-right reversal confusion. However, the ability to only pronounce and/or copy the target letter may not be enough to reduce confusion about the left-right reversal of a letter.

The difference in performance between 4-year-olds and older children suggests that the development of reversed image discrimination may be related to other types of cognitive functioning. Similar abilities known to be related to age differences are theory of mind (e.g., Perner, et al., 2007; Perner \& Ruffman, 1995), appearance-reality distinction (e.g., Flavell, Green, \& Flavell, 1986; Sapp, Lee, \& Muir, 2000), suggestibility (e.g., Bruck \& Ceci, 1999; Leichtman \& Ceci, 1995; Uehara, 2000), executive function (e.g., Lyons \& Zelazo, 2011; Zelazo \& Frye, 1998), and other functions (e.g., Gerstadt, Hong, \& Diamond, 1994; Povinelli, Landau, \& Perilloux, 1996; Uehara, 1998). However, the relationships among these abilities remain unclear. Zelazo (2004) proposed that reflective consciousness develops together with metacognitive skills and that this development could lead to the control of thought, emotion, and action. The development of metacognition and/or self-reflective consciousness may be one factor involved in the changes in performance that have been observed over a wide range of cognitive abilities, including reversal differentiation. In this manner, the use of conscious metacognitive judgment may lead to an avoidance of confusion when stimuli have similar appearances, such as with reversed images. Further investigation is necessary to elucidate the specific mechanisms underlying this process.

In conclusion, the present study demonstrates that, although the documented relationship between left-right confusion and linguistic skills is important, other factors also play critical roles in reversal confusion in young children. 


\section{Acknowledgements}

This research was supported by MEXT KAKENHI Grant Numbers 19730457. I thank Ikuya Murakami for his thoughtful comments on earlier versions of this paper and his help in submitting this paper. Most of all, I am grateful to the children and teachers at the nursery school for their cooperation.

\section{REFERENCES}

Bruck, M., \& Ceci, S. J. (1999). The suggestibility of children's memory. Annual Review of Psychology, 50, 419-439. http://dx.doi.org/10.1146/annurev.psych.50.1.419

Bryant, P. E. (1973). Discrimination of mirror images by young children. Journal of Comparative and Physiological Psychology, 82, 415-425. http://dx.doi.org/10.1037/h0034141

Cohn, M., \& Stricker, G. (1979). Reversal errors in strong, average, and weak letter namers. Journal of Learning Disabilities, 12, 533-537. http://dx.doi.org/10.1177/002221947901200808

Corballis, M. C., \& Zalk, M. C. (1977). Why do children confuse mirror-image obliques? Journal of Experimental Child Psychology, 24, 516-523. http://dx.doi.org/10.1016/0022-0965(77)90095-9

Cronin, V. (1967). Mirror-image reversal discrimination in kindergarten and first-grade children. Journal of Experimental Child Psychology, 5, 577-585. http://dx.doi.org/10.1016/0022-0965(67)90051-3

Cubelli, R., \& Della Sala, S. (2009). Mirror writing in pre-school children: A pilot study. Cognitive Processing, 10, 101-104. http://dx.doi.org/10.1007/s10339-008-0233-z

Davidson, H. P. (1935). A study of the confusing letters b, d, p, and q. Journal of Genetic Psychology, 47, 458-468.

Fisher, C. B., Bornstein, M. H., \& Gross, C. G. (1985). Left-right coding and skills related to beginning reading. Journal of Developmental \& Behavioral Pediatrics, 6, 279-283. http://dx.doi.org/10.1097/00004703-198510000-00009

Flavell, J., Green, F., \& Flavell, E. (1986). Development of knowledge about the appearance-reality distinction. Monographs of the Society for Research in Child Development, 51, i+iii+v+1-87. http://dx.doi.org/10.2307/1165866

Gerstadt, C., Hong, Y. J., \& Diamond, A. (1994). The relationship between cognition and action: Performance of children $31 / 2$ - 7 years old on a Stroop-like day-night test. Cognition, 53, 129-153. http://dx.doi.org/10.1111/j.1467-7687.2011.01105.x

Huttenlocher, J. (1967). Discrimination of figure orientation: Effects of relative position. Journal of Comparative and Physiological Psychology, 63, 359-361. http://dx.doi.org/10.1037/h0024398

Jean-Paul, F., \& Youssef, T. (2012). Unraveling the mystery of mirror writing in typically developing children. Journal of Educational Psychology, 104, 193-205. http://dx.doi.org/10.1037/a0025735

Jordan, B. T., \& Jordan, S. G. (1974). Jordan left-right reversal test. Child Psychiatry and Human Development, 4, 178-187. http://dx.doi.org/10.1007/BF01436026

Jordan, B. T., \& Jordan, S. G. (1990). Jordan left-right reversal test: An analysis of visual reversals in children and significance for reading problems. Child Psychiatry and Human Development, 21, 65-73. http://dx.doi.org/10.1007/BF00709929

Leichtman, M. D., \& Ceci, S. J. (1995). The effects of stereotypes and suggestions on preschoolers' reports. Developmental Psychology, 31, 568-578. http://dx.doi.org/10.1037//0012-1649.31.5.758
Lyons, K. E., \& Zelazo, P. D. (2011). Monitoring, metacognition, and executive function: Elucidating the role of self-reflection in the development of self-regulation. Advances in Child Development and Behavior, 40, 379-412.

http://dx.doi.org/10.1016/B978-0-12-386491-8.00010-4

Mandler, J. M., \& Stein, N. L. (1974). Recall and recognition of pictures by children as a function of organization and distractor similarity. Journal of Experimental Psychology, 102, 657-669. http://dx.doi.org/10.1037/h0036114

McMonnies, C. W. (1992a). Reversals and left/right confusion. Journal of Behavioral Optometry, 3, 31-34.

McMonnies, C. W. (1992b). Visuo-spatial discrimination and mirror image letter reversals in reading. Journal of the American Optometric Association, 63, 698-704.

Perner, J., Kloo, D., \& Gornik, E. (2007). Episodic memory development: Theory of mind is part of re-experiencing experienced events. Infant and Child Development, 16, 471-490. http://dx.doi.org/10.1002/icd.517

Perner, J., \& Ruffman, T. (1995). Episodic memory and autonoetic consciousness: Developmental evidence and a theory of child amnesia. Journal of Experimental Child Psychology, 59, 516-548. http://dx.doi.org/10.1006/jecp.1995.1024

Povinelli D. J., Landau, K. R., \& Perilloux, H. K. (1996). Self-recognition in young children using delayed versus live feedback: Evidence of a developmental asynchrony. Child Development, 67, 1540-1554. http://dx.doi.org/10.1111/j.1467-8624.1996.tb01813.x

Rudel, R. G., \& Teuber, H. L. (1963). Discrimination of direction of line in children. Journal of Comparative and Physiological Psychology, 56, 892-898. http://dx.doi.org/10.1037/h0046592

Sapp, F., Lee, K., \& Muir, D. (2000). Three-year-olds’ difficulty with the appearance-reality distinction: Is it real or is it apparent? Developmental Psychology, 36, 547-560.

http://dx.doi.org/10.1037//0012-1649.36.5.547

Terepocki, M., Kruk, R. S., \& Willows, D. M. (2002). The incidence and nature of letter orientation errors in reading disability. Journal of Learning and disabilities, 35, 214-233.

http://dx.doi.org/10.1177/002221940203500304

Thompson, G. B. (1975). Discrimination of mirror-image shapes by young children. Journal of Experimental Child Psychology, 19, 165176. http://dx.doi.org/10.1016/0022-0965(75)90157-5

Uehara, I. (1998). No transfer of visuomotor learning of button-pressing from right to left hands in right-handed four-year-olds. Perceptual \& Motor Skills, 87, 1427-1440. http://dx.doi.org/10.2466/pms.1998.87.3f.1427

Uehara I. (2000). Differences in episodic memory between four- and five-year-olds: False information versus real experiences. Psychological Reports, 86, 745-755.

http://dx.doi.org/10.2466/pr0.2000.86.3.745

Uehara, I. (March, 2012). Differentiation of left-right reversal figures and letters by young children. The 23rd Annual Meeting for of the Japan Society of Developmental Psychology, Nagoya. (in Japanese)

Zelazo, P. D. (2004). The development of conscious control in childhood. Trends in Cognitive Sciences, 8, 12-17. http://dx.doi.org/10.1016/j.tics.2003.11.001

Zelazo, P. D., \& Frye, D. (1998). Cognitive complexity and control: II. The development of executive function in childhood. Current Directions in Psychological Science, 7, 121-125. http://dx.doi.org/10.1111/1467-8721.ep10774761 